\title{
LA JUSTICIA ADMINISTRATIVA. CON ESPECIAL REFERENCIA AL TRIBUNAL DE LO CONTENCIOSO ADMINISTRATIVO ${ }^{1}$ \\ María Inés Aragón Salcido
}

\begin{abstract}
Resumen
En el presente documento se plantean algunas propuestas de reformas para contribuir a la justicia administrativa en el estado de Sonora.En México, es urgente contar con órganos autónomos anticorrupción a nivel federal y estatales responsables de combatir a la corrupción desde la perspectiva administrativa, dejando a las procuradurías el ámbito penal.
\end{abstract}

\begin{abstract}
This document raises some reform proposals to contribute to the administrative justice in the State of Sonora. In Mexico, it is urgent to have anti-comuption autonomous bodies at federal and State level, responsibles to combat comuption from the administrative perspective, leaving the criminal matter to the public attomey .

Sumario: Introducción. II. El Tribunal de lo Contencioso Administrativo del Estado de Sonora. III. Propuestas de reformas para contribuir a la justicia administrativa en el Estado de Sonora. IV. Conclusiones
\end{abstract}

\section{Introducción}

En el abordaje del tema, es necesario saber en qué consiste la jurisdicción administrativa. En efecto, Don Jesús González Pérez, nos dice que: "La jurisdicción administrativa,.. consiste en tribunales o juzgados independientes del Poder judicial y de la administración pública --sin la independencia del Ejecutivo no podría hablarse de jurisdicción-- a la que se atribuye el conocimiento o decisión de las pretensiones fundadas en derecho administrativo". ${ }^{3}$

\footnotetext{
1 Ponencia presentada en el marco del Foro sobre Justicia, convocado por el Partido Revolucionario Institucional, a través de su Consejo Político y la Fundación Colosio, A.C., Tema: Justicia Administrativa, en el ámbito local.

${ }^{2}$ Doctora en Derecho por la Universidad Nacional Autónoma de México UNAM, Catedrática de las asignaturas de Derecho Administrativo, Derecho Constitucional en la UNISON en diferentes épocas y en otras Universidades Nacionales Públicas y Privadas, y del Extranjero.

${ }^{3}$ González Pérez, Jesús; Vázquez Alfaro, José Luis (colaborador a partir de la segunda edición), Derecho procesal administrativo mexicano, 3a ed., México, Porrúa, 2005, t. I, p. 47.
} 
$Y$, tenemos que lanzar una mirada a nuestra historia sobre la jurisdicción administrativa. En en nuestro país, durante la época de la colonia si bien se caracterizó por seguir el modelo judicialista, en las controversias administrativas, la influencia española se hizo presente en los asuntos fiscales los cuales se resolvían en tribunales especiales y no en los ordinarios. En la etapa de la independencia $\mathrm{y}$, especialmente, en la primera constitución federalista de 1824 nos alineamos al modelo norteamericano, predominando el sistema judicialista; modelo que prevaleció en las constituciones centralistas de 1836 y 1843 . Es en 1853, con la famosa Ley Lares, -Don Teodosio Lares-que se adopta el modelo francés de Consejo de Estado, -era el órgano encargado de conocer los asuntos contenciosos administrativos-, sustrayéndolo de la jurisdicción y competencia del poder judicial. Con el restablecimiento del federalismo en 1847, se retoma el sistema judicialista, el cual se confirma en la Constitución Federalista de 1857. Situación que se reitera en la Constitución Federalista de $1917 .{ }^{4}$

En 1936, retomamos el modelo francés cuando se crea el Tribunal Fiscal de la Federación. Posteriormente, en la institucionalizarían del modelo, se hicieron las reformas constitucionales de 1946, 1967 y $1987,{ }^{5}$ reconociendo constitucionalmente los tribunales administrativos con plena autonomía para dictar sus fallos.

Actualmente, tenemos el Tribunal Federal Fiscal y de Justicia Administrativa y sus homólogos, los tribunales de lo contencioso administrativo en la mayoría de las entidades federativas.

Con la reforma del artículo 116, fracción V, de la Constitución Federal, en 1987, se crearon la mayoría de los tribunales de lo contencioso administrativo en las entidades federativas, al establecer que: Las constituciones y leyes de los Estados podrán instituir Tribunales de lo Contencioso- Administrativo dotados de plena autonomía para dictar sus fallos, que tengan a su cargo dirimir las controversias que se susciten entre la Administración Pública Estatal y los particulares, estableciendo las normas para su organización, su funcionamiento, el procedimiento y los recursos contra sus resoluciones" ${ }^{\prime 6}$ se crearon en los estados diversos tribunales administrativos.

\footnotetext{
${ }^{4}$ Fernández Ruiz, Jorge, Derecho Administrativo de Aguas Calientes, Universidad Nacional Autónoma de México y Editorial Porrúa México, 2006, pp.125 y 128.

${ }^{5}$ Rives Sánchez, Roberto, La Reforma Constitucional en México, Universidad Nacional Autónoma de México, Primera edición, 2010, pp. 285, 286 y 328.

6 Ibidem p.328
} 


\section{El Tribunal de lo Contencioso Administrativo del Estado de Sonora.}

En el artículo 64, fracción XLIII Bis de la Constitución Política del Estado de Sonora se faculta al Congreso del Estado: Para instituir Tribunales de lo Contencioso Administrativo dotados de plena autonomía para dictar sus fallos, que tengan a su cargo dirimir las controversias que se susciten entre la administración pública y los particulares, estableciendo las normas para su organización, funcionamiento, procedimiento, y los requisitos que deben reunir él o los Magistrados. Y, en la fracción XXIV del artículo 80, se le otorgó al gobernador del estado la facultad para: Nombrar y remover libremente al Secretario y Subsecretario de Gobierno, Procurador General de Justicia y Tesorero General del Estado, y hacer la designación de los Magistrados del Supremo Tribunal de Justicia y del Tribunal de lo Contencioso Administrativo, sometiéndola a la aprobación del Congreso. $^{7}$

En 1977, la Ley Orgánica del Tribunal de lo Contencioso-Administrativo, en el artículo $1^{\circ}$, establece: El Tribunal de lo Contencioso-Administrativo del Estado de Sonora, es un tribunal administrativo dotado de plena autonomía, con la organización y atribuciones que esta Ley establece.

\section{A).-Competencia del Tribunal de lo Contencioso- Administrativo}

En el Artículo 19, de su Ley Orgánica, se establece: El Tribunal de lo Contencioso - Administrativo conocerá de los juicios que se inicien en contra de las resoluciones definitivas que se indican a continuación:

I. Las dictadas por autoridades fiscales estatales en que se determine la existencia de una obligación fiscal, se fije en cantidad líquida o se den las bases para su liquidación;

II. Las que nieguen la devolución de un ingreso de los regulados por el Código Fiscal, indebidamente percibidos por el Estado;

III. Las que causen un agravio en materia fiscal, distinto al que se refieren las fracciones anteriores;

\footnotetext{
${ }^{7}$ Aragón Salcido, María Inés, Coordinadora, La Constitución Política del Estado de Sonora de 1917 y sus Reformas(Marco Histórico-Constitucional 1831-1917), publicado por el Instituto Sonorense de Administración Pública, Hermosillo, Sonora, 1997, pp 133 y 150.
} 
IV. Las que impongan multas por infracción a las normas administrativas estatales; y

V. Las demás que otras leyes dispongan.

Para los efectos del primer párrafo de este artículo, las resoluciones se considerarán definitivas cuando no admitan recurso administrativo.

Y, en el Articulo 2, se establece que: El Tribunal de lo Contencioso - Administrativo conocerá de los juicios que promuevan las autoridades para que sean nulificadas las resoluciones administrativas favorables a un particular, siempre que dichas resoluciones sean de las materias previstas en el artículo anterior.

La Ley del Servicio Civil, en el Artículo Sexto transitorio, prescribe: "En tanto se instala y constituye el Tribunal de Conciliación y Arbitraje conocerá de los asuntos previstos por el artículo 112 de la presente ley el Tribunal Unitario de lo Contencioso Administrativo del Estado de Sonora". En consecuencia, a partir de 1977, por dicha disposición, le corresponde ejercer las facultades que se señalan en el Artículo 112 de la Ley del Servicio Civil al El Tribunal de Conciliación y Arbitraje y son:

I. Conocer de los conflictos individuales que se susciten entre los titulares de una entidad pública y sus trabajadores;

II. Conocer de los conflictos colectivos que surjan entre las organizaciones de trabajadores y las entidades públicas regidas por esta ley;

III. Conceder el registro de los sindicatos y de la federación de éstos o, en su caso, cancelar dichos registros;

IV. Conocer de los conflictos sindicales e intersindicales, y

V. Efectuar el registro de las condiciones generales de trabajo

B). Integración del Tribunal de lo Contencioso- Administrativo

El artículo 3o de la Ley Orgánica del Tribunal de lo Contencioso Administrativo del Estado de Sonora establece:

El Tribunal de lo Contencioso-Administrativo, se compondrá de un Magistrado Propietario y un Suplente, nombrados cada 6 años, pudiendo ser reelectos, y tomarán posesión de su encargo el día 16 de septiembre del año en que se inicie el periodo constitucional del Ejecutivo. Si por cualquier motivo no se hace nombramiento o los designados no se presentan al desempeño de su cargo, continuarán en funciones los individuos que los formen hasta que tomen posesión los nuevamente nombrados. Los que fueren nombrados en el curso del período desempeñarán sus funciones hasta la conclusión del mismo.

Podrá haber también Magistrados Supernumerarios, cuando las labores del Tribunal lo ameriten, cuya designación se hará en la misma forma y los mismos requisitos que al Magistrado Propietario. 
Por lo que hace al procedimiento, en el Código Fiscal del Estado de Sonora, en el Título Sexto, intitulado Del Procedimiento Contencioso Administrativo, Capítulo I, Disposiciones Generales, se prescribe en los artículos 196 y 197, lo siguiente:

ARTíCULO 196.-Los juicios que se promuevan ante el Tribunal de lo Contencioso Administrativo del Estado de Sonora se substanciarán y resolverán con arreglo al procedimiento que determina este Código. A falta de disposición expresa se aplicarán las prevenciones del Código del Procedimientos Civiles del Estado, siempre que la disposición de este último Ordenamiento no contravenga al procedimiento contencioso que establece este Código.

En los casos en que la resolución impugnada afecte los intereses jurídicos de dos o más personas, y éstas promuevan juicio, en el escrito inicial de la demanda deberán designar un representante común que elegirán de entre ellas mismas, y si no lo hicieren, el magistrado designará con tal carácter a cualquiera de los interesados al admitir la demanda.

Cuando la resolución recaída a un recurso administrativo no satisfaga el interés jurídico del recurrente y éste la controvierta, se entenderá que simultáneamente impugna la resolución recurrida en la parte que continúe afectándolo, pudiendo hacer valer conceptos de impugnación no planteados en el recurso.

ARTíCULO 197.- En los juicios que los juicios que se promuevan ante el Tribunal de lo Contencioso Administrativo del Estado de Sonora se substanciarán y resolverán con arreglo al procedimiento que determina este Código. A falta de disposición expresa se aplicarán las prevenciones del Código de Procedimientos Civiles del Estado, siempre que no contravenga al procedimiento contencioso que establece este Código.

\section{Propuestas de reformas para contribuir a la justicia administrativa en el Estado de Sonora.}

La experiencia de 37 años del Tribunal de lo Contencioso Administrativo del Estado de Sonora, en el contexto actual, amerita una revisión de su estructura, funcionamiento y competencia.

Al día de hoy, se tienen radicados en el Tribunal 685 expedientes, de los cuales se estima que el $70 \%$ son asuntos del orden burocrático y el $30 \%$ asuntos fiscales y administrativos, en estos últimos están incluidos los recursos en materia de responsabilidades de los servidores públicos, información proporcionada por personal del Tribunal.

Una de las propuestas, que desde hace tiempo, se ha venido presentando en diversos foros, es el relativo a que se establezca el Tribunal de Conciliación y Arbitraje para los Trabajadores del Servicio Civil del Estado, dando cumplimiento a lo establecido en la Ley del Servicio Civil. Cabe mencionar como dato histórico que Sonora es el único 
estado de la República Mexicana en el que el Tribunal de lo Contencioso Administrativo conoce de la materia de derecho burocrático.

El punto central de los tribunales locales de lo contencioso administrativos en México, es la de fortalecer su competencia y acercar el acceso de la justicia administrativa a los ciudadanos, para dar cumplimiento a lo dispuesto por el artículo 17 constitucional, de manera pronta, completa e imparcial; tema que ha ocupado infinidad de foros académicos y de la asociación de los magistrados de dichos tribunales en nuestro país, con diversas propuestas desde la óptica de empotrarlos en el poder judicial o dejarlos como organismos autónomos.

Lo interesante en este momento, respecto del fortalecimiento de la competencia de dichos tribunales, es que se encuadra en el tema del combate a la corrupción, que ha sido ampliamente examinado en el Senado de la República y las diversas propuestas que se presentaron por los grupos parlamentarios se llegaron a consensar en el: Dictamen de las Comisiones Unidas de Puntos Constitucionales, de Gobernación, de Anticorrupción y Participación Ciudadana y de Estudios Legislativos Primera, Con Proyecto de Decreto que Reforma y Adiciona Diversos Artículos de la Constitución Política de los Estados Unidos Mexicanos, en Materia de Combate a la Corrupción, ${ }^{8}$ el cual después de un largo proceso, "previo el desarrollo de una metodología de trabajo en la que:

\footnotetext{
${ }^{8}$ Dictamen de las Comisiones Unidas de Puntos Constitucionales, de Gobernación, de Anticorrupción y Participación Ciudadana y de Estudios Legislativos Primera, Con Proyecto de Decreto que Reforma y Adiciona Diversos Artículos de la Constitución Política de los Estados Unidos Mexicanos, en Materia de Combate a la Corrupción, www. senado.gob.mx/doc , pp. 1-3

I. Con fecha 15 de noviembre de 2012 senadoras senadores integrantes del Grupo Parlamentario del Partido Revolucionario Institucional y del Partido Verde Ecologista de México de la LXII Legislatura del Honorable Congreso de la Unión presentaron una Iniciativa con Proyecto de Decreto que Reforma y Adiciona los Artículos 22, 73, 79, 105, 107, 109, 113, 116 Y 122 de la Constitución Política de los Estados Unidos Mexicanos para combatir la corrupción. Turnándose a las Comisiones de Puntos Constitucionales, de Estudios Legislativos Primeras y a la de Anticorrupción y Participación Ciudadana para su estudio y dictamen, con opinión de la Comisión de Gobernación.

II. Con fecha 20 de noviembre de 2012, senadoras y senadores integrantes del Grupo Parlamentario del Partido de la Revolución Democrática de la LXII Legislatura del Honorable Congreso de la Unión presentaron una Iniciativa, Con Aval de Grupo, que Contiene Proyecto de Decreto que Reforma los Artículos 21, 73, 76, 105, 109 y 110 de la Constitución Política de los Estados Unidos Mexicanos, para combatir la corrupción. Turnándose a las Comisiones de Puntos Constitucionales y de Estudios Legislativos Primera, con opinión de las Comisiones de Gobernación y de Anticorrupción y participación Ciudadana.
}

III. Con fecha 30 de enero de 2013, el Senador José María Martínez y Martínez integrante del Grupo Parlamentario del Partido de Acción Nacional de la LXII Legislatura del Honorable Congreso de la Unión presentó a la Comisión Permanente una Iniciativa con Proyecto de Decreto que Reforma los Artículos 16, 21, 76 Y 109 de la Constitución Política de los Estados Unidos Mexicanos y se Expide la Ley Orgánica del Instituto Nacional Anticorrupción y de Control, también para combatir la corrupción. Turnándose a las Comisiones de Puntos Constitucionales y de Anticorrupción y Participación Ciudadana para su estudio y dictamen.

IV.- Con fecha 4 de abril de 2013 los Senadores Ernesto Javier Cordero Arroyo, María del Pilar Ortega Martínez, Laura Angélica Rojas Hernández, Fernando Torres Graciano y Salvador Vega Casillas, con aval del Grupo Parlamentario del Partido Acción Nacional, presentaron una Iniciativa 
a) Se procedió a describir las Iniciativas a fin de clarificar, ordenar y establecer los objetivos que se pretenden alcanzar.

b) Se estudiaron los modelos anticorrupción que proponen las Iniciativas y se examinó si el contenido normativo planteado contribuye o no al logro de los objetivos pretendidos así como la viabilidad de su implantación.

c) Se hicieron estudios de derecho comparado y se revisaron los compromisos adquiridos por México en materia de anticorrupción en distintos instrumentos internacionales.

d) Se incluyeron los posicionamientos y opiniones que hicieron los expertos, especialistas y representantes de las organizaciones de la sociedad civil así como de la Comisión coadyuvante, según se expuso en los Antecedentes de este Dictamen y

e) Se expusieron en los considerandos las razones por las cuales se incluyeron o se excluyeron del articulado del dictamen cada uno de los planteamientos contenidos en las Iniciativas"'.

En este contexto, el Dictamen de la Cámara de Senadores, presenta en su Iniciativa, la creación de un organismo público autónomo ${ }^{10}$ que estará a cargo de

que contiene proyecto de decreto por el que se reforman y adicionan diversos artículos de la Constitución Política de los Estados Unidos Mexicanos, a efecto de crear el Sistema Nacional de Combate a la Corrupción.

${ }^{9}$ Ibídem pp. 3 y 4

${ }^{10}$ Artículo 73. ...

I. a XXIX-G. ...

XXIX-H. Para expedir leyes que instituyan tribunales de lo contencioso-administrativo, dotados de plena autonomía para dictar sus fallos, estableciendo las normas para su organización, su funcionamiento, los procedimientos y los recursos contra sus resoluciones, los cuales tendrán a su cargo dirimir las controversias que se susciten entre la administración pública federal y los particulares, así como para conocer de las impugnaciones en contra de sanciones a los servidores públicos de la Federación por responsabilidad administrativa, impuestas por autoridades distintas al órgano federal a que se refiere el artículo 113 de esta Constitución.

Artículo 113.- El órgano responsable de combatir la corrupción estará a cargo de la prevención, investigación y sanción de las responsabilidades administrativas que deriven de los hechos de corrupción así calificados por la ley, cometidos por los servidores públicos de la Federación, así como por cualquier persona física o moral involucrada en tales actos o que resulte beneficiada por los mismos y, en vía de atracción, conocerá de aquellos hechos competencia de las entidades federativas y los municipios, en los términos que establezca la ley.

El órgano responsable de combatir la corrupción es un organismo público autónomo, con personalidad jurídica y patrimonio propio. El órgano será dirigido por un Titular nombrado por la Cámara de Senadores a propuesta de los Grupos Parlamentarios, con el voto de las dos terceras partes de los miembros presentes, siguiendo el proceso establecido en la ley. El nombramiento 
la prevención, investigación y sanción de las responsabilidades administrativas que deriven de los hechos de corrupción así calificados por la ley, cometidos por los servidores públicos de la Federación, así como por cualquier persona física o moral involucrada en tales actos o que resulte beneficiada por los mismos y, en vía de atracción, conocerá de aquellos hechos competencia de las entidades federativas y los municipios, en los términos que establezca la ley. Y, en lo que concierne a los tribunales de lo contencioso administrativo, estos estarán facultados para conocer de las impugnaciones en contra de sanciones a los servidores públicos de la Federación por responsabilidad administrativa, impuestas por autoridades distintas al órgano federal a que se refiere el artículo 113 de esta Constitución.

Dictamen que se turnó a la Cámara de Diputados en marzo 11, 2014, a solicitud de la excitativa del senador Armando Ríos Piter, el cual se remitió a la Cámara de Diputados

$Y$, recientemente, la Iniciativa que reforma y adiciona diversas disposiciones de la Constitución Política de los Estados Unidos Mexicanos, suscrita por diputados y senadores del Grupo Parlamentario del PAN, propone la creación de un Sistema Nacional Anticorrupción.

En el tema de los tribunales contencioso administrativo, propone en el Artículo 116, fracción V, lo siguiente:

Las Constituciones y leyes de los Estados deberán instituir Tribunales de Justicia Administrativa, dotados de plena autonomía para dictar sus fallos y establecer su organización, funcionamiento, procedimientos y, en su caso, recursos contra sus resoluciones. Los

podrá ser objetado por el Presidente de la República en un plazo de diez días hábiles. Si el Presidente de la República no objetara el nombramiento dentro de dicho plazo, ocupará el cargo la persona nombrada por el Senado.

En caso de que el Presidente de la República objetara el nombramiento, la Cámara de Senadores hará uno nuevo en los términos del párrafo anterior, pero con una votación de las tres quintas partes de los miembros presentes. Si este segundo nombramiento fuera objetado, la Cámara de Senadores en los términos del párrafo anterior, con la votación de las tres quintas partes de los miembros presentes, designará al Titular.

El Titular del órgano responsable de combatir la corrupción deberá cumplir los mismos requisitos que se establecen en el Apartado A del artículo 102 de esta Constitución, salvo que la antigüedad de su título profesional podrá ser en cualquier disciplina afín a la función; desempeñará su encargo por un período de siete años improrrogable; sólo podrá ser removido en los términos del presente Título, y no podrá tener ningún otro empleo, cargo o comisión, con excepción de aquéllos no remunerados en actividades docentes, científicas, culturales o de beneficencia. 
Tribunales tendrá a su cargo dirimir las controversias que se susciten entre la administración pública local y municipal y los particulares; imponer las sanciones a los servidores públicos locales y municipales por responsabilidad administrativa de las faltas graves que se establezcan en la ley, y a los particulares que incurran en actos de corrupción en los términos que determinen las leyes; imponer, en su caso, la responsabilidad resarcitoria, las indemnizaciones $y$ sanciones pecuniarias que deriven de los daños y perjuicios que afecten a la Hacienda Pública Estatal o Municipal o al patrimonio de los entes públicos locales o municipales.

\section{Conclusiones}

Es urgente establecer en el estado de Sonora, el Tribunal de Conciliación y Arbitraje para los Trabajadores del Servicio Civil del Estado, dando cumplimiento a lo establecido en la Ley del Servicio Civil.

En México, es urgente contar con órganos autónomos anticorrupción a nivel federal y estatales responsables de perseguir a la corrupción desde la perspectiva administrativa, dejando a las procuradurías el ámbito penal, siguiendo el modelo consensado en la Cámara de Senadores y buscar los puntos de acuerdo con la última Iniciativa presentada en la Cámara de Diputados, finalmente lo que se pretende es contar con el marco jurídico para combatir eficazmente contra la corrupción.

Habrá que esperar la decisión del Poder Constituyente Permanente de la Unión, en la reforma integral contra la corrupción, con los enfoques: preventivo y punitivo, para determinar cuál será el papel que desempeñarán los tribunales de lo contencioso administrativo en nuestro país en el combate a la corrupción, es decir, continuar como tribunales de legalidad o convertirlos en órganos sancionadores.

En la administración pública, se parte de la buena fe y su punto de partida es la legalidad; por ello, tan importante la revisión del marco jurídico mexicano a la luz de los estándares internacionales de los derechos humanos y de los modelos anticorrupción. 
La homologación con leyes generales, es una buena estrategia en el federalismo cooperativo, distribuyendo competencias en los diversos órdenes de gobierno dentro de una misma lógica: fortalecer el estado de derecho.

\section{Bibliografía y Webgrafía}

ARAGÓN SALCIDO, María Inés, Coordinadora, La Constitución Política del Estado de Sonora de 1917 Y Sus Reformas(Marco Histórico-Constitucional 18311917), publicado por el Instituto Sonorense de Administración Pública, Hermosillo, Sonora, 1997.

FERNÁNDEZ RUIZ, Jorge, Derecho Administrativo de Aguas Calientes, Universidad Nacional Autónoma de México y Editorial Porrúa México, 2006.

GONZÁLEZ PÉREZ, Jesús, Derecho procesal administrativo mexicano, 3a ed., México, Porrúa, 2005

RIVES SÁNCHEZ, Roberto, La Reforma Constitucional en México, Universidad Nacional Autónoma de México, Primera edición, 2010.

DICTAMEN de las Comisiones Unidas de Puntos Constitucionales, de Gobernación, de Anticorrupción y Participación Ciudadana y de Estudios Legislativos Primera, con Proyecto de Decreto que Reforma y Adiciona Diversos Artículos de la Constitución Política de los Estados Unidos Mexicanos, en Materia de Combate a la Corrupción, www. senado.gob.mx/doc. [consultado el 15 de noviembre de 2014]

INICIATIVA con proyecto de decreto que reforma, adiciona y deroga diversas disposiciones a los artículos 22, 73, 74, 76, 79, 109, 113, 114, 116 y 122 de la Constitución Política de los Estados Unidos Mexicanos. www.pan.org.mx/wpcontent/uploads/.../Iniciativa-Anticorrupcion.pdf [consultado el 15 de noviembre de 2014] 